\title{
Mujeres solas en la posguerra española (1939-1949). Estrategias frente al hambre y la represión
}

Francisco Alía Miranda, Óscar Bascuñán Añover, Herminia Vicente Rodríguez-Borlado, Alfonso M. Villalta Luna Francisco.Alia@uclm.es / ogbascunan@hotmail.com / triqlban@hotmail.com am.villalta@hotmail.com

Fecha recepción: 28.11.2015 / Fecha aceptación 04.04.2016

\section{Resumen}

El artículo tiene como objetivo fundamental el análisis del protagonismo adquirido por las mujeres españolas durante la posguerra (1939-1949) en la supervivencia de la unidad familiar. Mucha de ellas fueron «mujeres solas» que, con sus maridos en las cárceles o muertos en la guerra o a consecuencia de la represión del régimen vencedor, tuvieron que sacar adelante a sus familias. Prácticamente su único objetivo en estos años era sobrevivir, para lo que utilizaron numerosas estrategias. Entre ellas, la principal fue la del robo y el hurto hacia la propiedad. A través de

\begin{abstract}
This paper aims chiefly to analyze the prominence achieved by Spanish women during the post-war period (1939-1949) in regards to the survival of the family unit. Many of them were "single women" who had to help their families succeed, while their husbands were imprisoned, killed at war or even repressed by the victorious regime. At that time, the principal aim was survival, and many strategies were used by those single women for this purpose. They included mainly theft and burglary but not exclusively. Using legal sources, “women's delinquency" is analyzed with the provinces of Castilla-
\end{abstract}

\footnotetext{
* Este trabajo es resultado de distintos proyectos de investigación: "Familia, desigualdad y cambio generacional en la España interior, siglos XVIII-XIX” (HAR2013-48901-C6-6-R), del Ministerio de Economía y Competitividad; “Conflicto social y protesta popular en Castilla-La Mancha, 1850-1950" (PEII-2014-024-P), de la Junta de Comunidades de Castilla-La Mancha (Consejería de Educación, Cultura y Deportes), cofinanciado por el Fondo Europeo de Desarrollo Regional; y Proyecto 92.1 del Ministerio de la Presidencia: "Todos los nombres de la represión de posguerra en Ciudad Real: investigación y material didáctico”, Departamento de Antropología Social y Cultural de la UNED.
} 
las fuentes judiciales, se estudia la «delincuencia femenina» en un escenario principal, CastillaLa Mancha, siempre con un método comparado con otros territorios ya investigados por especialistas del franquismo. Además, se comparan los delitos contra la propiedad cometidos por las mujeres en la posguerra con los sucedidos antes de la guerra civil, con el fin de explicar las posibles similitudes y diferencias.

\section{Palabras clave}

Represión franquista, Posguerra, Hambre, Mujeres, Delincuencia.
La Mancha being the principal geographical frame, yet without straying from a comparative approach in order to keep in mind other territories already researched by specialists of Francoist History. Moreover, crimes against property committed by those single women during the post-war period are compared to the "female criminality" of the period before the civil war, with a view to exploring any similarities and differences.

\section{Key words}

Franquismo repression, post-war Spain, hunger, women, criminality. 


\section{Introducción}

Al finalizar la guerra civil española en abril de 1939, las nuevas autoridades franquistas comenzaron la persecución de los considerados vencidos con efectos retroactivos desde octubre de 1934, como marcaba la Ley de Responsabilidades Políticas aprobada casi dos meses antes de acabar la contienda. La represión fue, en palabras del profesor Moradiellos, «una política social de "limpieza y depuración" de enemigos y desafectos enormemente fructífera para la dictadura franquista, sin la cual no resulta cabalmente comprensible su consolidación y pervivencia durante tantos años y en tan diferentes contextos internacionales» ${ }^{1}$.

Ejecuciones, tortura y miedo eran rasgos cotidianos de los primeros años de vida del nuevo régimen. Los datos totales o parciales disponibles sobre treinta y tres provincias indican que hubo más de 35.000 ejecuciones, ya contabilizadas, en la posguerra. A finales de 1939 y durante 1940 las fuentes oficiales contabilizaban más de 270.000 reclusos. Hasta octubre de 1941 se habían abierto 125.286 expedientes siguiendo la Ley de Responsabilidades Políticas de febrero de 1939 y unas 200.000 personas más sufrieron la fuerza de la justicia de esa ley en los años siguientes. En 1943 había todavía más de 100.000 presos y 15.947 personas purgaban en ese mismo año sus penas en los 121 destacamentos penales que, desperdigados por toda la geografía española, empleaban a los presos para trabajos de reconstrucción, en carreteras o pantanos ${ }^{2}$.

En la mayor parte de los numerosos estudios publicados en los últimos años por casi toda la geografía española sobre la represión, ésta se ha estudiado privilegiando el aspecto cuantitativo y político, explicándola generalmente como una venganza por los acontecimientos sucedidos durante los años de guerra, como una expresión de la violencia de estado generalmente desvinculada del prolongado desarrollo histórico precedente a la guerra civil,

1. E. Moradiellos, La España de Franco (1939-1975). Política y sociedad, Madrid, 2000, 237.

2. J. Casanova, "Una dictadura de cuarenta años", en J. Casanova (Coord.), Morir, matar, sobrevivir. La violencia en la dictadura de Franco, Barcelona, 2002, 20-25. 
o sencillamente como una manifestación exclusiva de la naturaleza autoritaria y profundamente y antidemocrática del nuevo régimen político ${ }^{3}$.

La mayor parte de estos trabajos coinciden en que la represión tuvo múltiples caras. Porque, como opina el profesor Ortiz Heras ${ }^{4}$, había otras formas de violencia menos draconianas, jen apariencia!, que la eliminación física de los considerados enemigos, como eran la violencia administrativa, los efectos de la ley de vagos y maleantes, la justicia ordinaria, el control social, la violencia laboral, la violencia moral, la violencia de género, el mundo penitenciario, la violencia contra la cultura y la educación. Cada momento tuvo su estrategia.

A estas formas de violencia, la profesora Conxita Mir ha propuesto sumar, con acierto, los «efectos no contables de la represión», es decir, las defunciones provocadas por el hambre, la desnutrición o la enfermedad impuesta, más o menos voluntariamente, por los responsables de administrar alimentos de primera necesidad, en un sistema autárquico caracterizado por el control extremo de la producción y el comercio, o la precaria y caprichosa sanidad «pública» que en no pocos casos se gestionaron como auténticos mecanismos de coerción ${ }^{5}$.

Las últimas tendencias de la historiografía especializada proponen explorar nuevos campos de estudio relacionados con la historia social. Entre otros temas, "podría decirse que es la hora de estudiar la represión sobre los vivos, sobre la mayoría superviviente de la guerra y la posguerra que vivió bajo lustros de franquismo» ${ }^{6}$.

Uno de los temas que está consiguiendo resultados más significativos es el del estudio de las duras condiciones de vida durante la España de la posguerra interrelacionado con la represión y la violencia institucionalizada y la coacción cotidiana ejercida sobre las clases sociales más humildes, sobre las que se implantó un férreo control social por medio de numerosos mecanismos, incluido, para muchos, el propio racionamiento de alimentos. La autarquía, por tanto, no puede ser vista sólo como una política económica sino también como un medio de dominación política ${ }^{7}$.

3. F. Cobo Romero: La represión franquista en Andalucía. Sevilla, 2012. Para este autor, lo que explica la cuantificación de las víctimas, su procedencia geográfica, su naturaleza socio-profesional y su identificación política e ideológica es el resultado de un cúmulo de factores que remontan su gestación a un prolongado período de tiempo precedente cuyo inicio debe situarse en los albores del siglo XX, caracterizado por la movilización obrera. Esta obra supone casi una excepción a la tónica dominante que desvincula la represión de posguerra del devenir histórico anterior a la II República y al conflicto.

4. M. Ortiz Heras, La violencia política en la Dictadura Franquista, 1939-1977. La insoportable banalidad del mal, Albacete, 2013.

5. C. Mir Cucó, Vivir es sobrevivir. Justicia, orden y marginación en la Cataluña rural de posguerra, Lleida, 2000.

6. J. Ponce Alberca e I. Sánchez González: "No sólo represión. Dictadura franquista, conceptos históricos y categorías morales", Hispania Nova, 10, 2012.

7. Entre otros muchos, pueden verse los estudios de J. Casanova, F. Espinosa, C. Mir y F. Moreno, en J. Casanova (Coord.), op. cit.; A. Cazorla Sánchez, Las políticas de la victoria. La consolidación del Nuevo Estado franquista (1938-1953), Madrid, 2000; Á. Cenarro, "Muerte y subordinación en la España franquista: el imperio de la violencia como base del nuevo Estado”, Historia Social, 30, 1998, 
Estos trabajos generales han venido siendo completados con investigaciones en el ámbito provincial que, a partir de fuentes judiciales, han permitido conocer las necesidades de hombres y mujeres a través de los delitos económicos, cometidos principalmente con la finalidad de sobrevivir. Hasta ahora conocíamos bien territorios como Almería, Albacete, Lleida, Murcia y Tarragona ${ }^{8}$.

El hambre y la miseria de la posguerra provocaron un creciente protagonismo de las mujeres ante la subsistencia, muchas de ellas viudas de guerra o de la represión franquista o esposas de presos políticos que tuvieron que luchar por la supervivencia del núcleo familiar. Precisamente porque eran madres y esposas se vieron obligadas a reinventar estrategias de supervivencia para sí y su entorno. La represión las dejó solas. Como escribe $\mathrm{M}^{\mathrm{a}}$ Carmen García Nieto: «Las mujeres con sus hombres y padres en la cárcel o sin trabajo se vieron obligadas a realizar todo tipo de trabajos, duros y mal pagados, o no pagados, gratuitos o cambio de la comida: el campo, el ganado, ir a por agua, servir en las casos de los ricos del pueblo o en la ciudad»?.

En situaciones límite se vieron abocadas al delito: robos y hurtos contra la propiedad con el fin de poder alimentar a sus familias, que en muchos casos habían perdido al padre o al marido por la política. Las cárceles franquistas se fueron llenando de mujeres condenadas por delitos de carácter económico. Estas aumentaban conforme iban disminuyendo las presas políticas.

A pesar del protagonismo adquirido por las mujeres en estos años de extrema dificultad, reconocido en todos los trabajos especializados antes apuntados, apenas hay estudios centrados en ellas que abunden en sus actividades y expliquen sus necesidades ${ }^{10}$. En este artículo las mujeres son las únicas protagonistas. A partir de ellas se aborda el objetivo principal del trabajo: Estudiar cómo afectó la represión del régimen franquista a las familias de los represaliados. Mujeres solas que como madres, mujeres, viudas o hijas de republicanos presos o ejecutados tuvieron que luchar día a día por sacar adelante a sus familias en un contexto difícil por el hambre, la miseria y el estrecho control social de un régimen que las

5-22; C. Mir Curcó, op. cit.; y M. Richards, Un tiempo de silencio. La guerra civil y la cultura de la represión en la España de Franco, 1936-1945, Barcelona, 1999.

8. F. Gómez Westermeyer, Historia de la delincuencia en la sociedad española: Murcia, 1939-1949. Similitudes y diferencias en otros espacios europeos, Tesis doctoral Universidad de Murcia, 2007; C. Mir Curcó, op. cit.; M. Ortiz Heras, Violencia política en la II República y el Primer Franquismo: Albacete, 1936-1950, Madrid, 1996; M. Ortiz Heras (Coord.), Memoria e historia del franquismo. V Encuentro de Investigadores del franquismo, Cuenca, 2005; Ó. J. Rodríguez Barreira, Migas con miedo. Prácticas de resistencia al primer franquismo. Almería, 1939-1953, Almería, 2008.

9. M. C. García Nieto, “Trabajo y oposición popular de las mujeres durante la dictadura franquista” en G. Duby y M. Perrot (Dirs.), Historia de las Mujeres V. El Siglo XX, Barcelona, 1994, 666.

10. Una de las pocas excepciones lo constituye E. Barranquero Texeira y L. Prieto Borrego, Así sobrevivimos al hambre: estrategias de supervivencia de las mujeres en la posguerra española, Málaga, 2003. La investigación se basa, principalmente, en las fuentes orales ( $88 \%$ de entrevistas a mujeres y $12 \%$ a hombres). También el trabajo de I. Murillo Aced, En defensa de mi hogar y mi pan. Estrategias femeninas de resistencia civil y cotidiana en la Zaragoza de posguerra, 1936-1945, Zaragoza, 2012. 
vigilaba constantemente tanto «desde arriba como desde abajo». En este momento de extrema dificultad tomaba más importancia si cabe el protagonismo de la mujer como agente de cambio social ${ }^{11}$.

Estas mujeres solas tuvieron que ponerse al frente de la unidad familiar y salir a la calle en busca de alimentos para los suyos en el mercado oficial, caracterizado por el control en precios y en la distribución de productos (racionamiento), y en el mercado negro extraoficial, obligado para la mayor parte de españoles por las carencias del primero. No había otra alternativa. Unas consiguieron hacerlo siguiendo los cauces legales; otras lo lograron solamente saltándose los límites de la justicia, por falta de recursos o por las dificultades que establecía para ellas el férreo control social del régimen.

Estas últimas, las «mujeres delincuentes», son el centro de la investigación porque conseguimos seguir su rastro a través de las sentencias judiciales que las condenaban tras su arresto por las fuerzas de seguridad del Estado ${ }^{12}$. El estudio se ha centrado en un ámbito prácticamente inédito en el contexto nacional como es el de Castilla-La Mancha (del que sólo se había estudiado la provincia de Albacete), aunque se realiza con una metodología comparada a partir de los casos provinciales y regionales ya conocidos. La reducción del espacio geográfico ha permitido profundizar en el objetivo impuesto a partir de un riguroso análisis de todas las sentencias que se impartieron por las Audiencias Provinciales de Albacete, Ciudad Real, Cuenca, Guadalajara y Toledo entre 1940 y 1949. También ha permitido abordar de forma totalmente inédita un aspecto que considerábamos importante para la comprensión global de la temática analizada: el estudio en perspectiva histórica. En este trabajo se analiza la delincuencia femenina en la posguerra y la previa a la guerra con el fin de obtener semejanzas y diferencias, explorar las posibles nuevas estrategias surgidas durante el régimen franquista y explicar el fenómeno de la necesidad de delinquir de muchas mujeres solas en la posguerra.

\section{La estrategia femenina en los delitos contra la propiedad antes de la Guerra Civil}

La conflictividad social en un territorio mayoritariamente rural como Castilla-La Mancha y con una numerosa población campesina no puede ser explicada solo a través de las acciones de un movimiento obrero concentrado en ámbitos urbanos e industriales muy concretos. Motines espontáneos contra las subidas o escasez de subsistencias, revueltas populares contra los impuestos, manifestaciones, algaradas y otras muchas expresiones de desórdenes públicos y acciones de protesta de carácter informal fueron frecuentes por las tierras castella-

11. Véanse, F. Thebaud, “Le temps du gender", en Ecrire l'histoire des femmes, Fontenay-aux-Roses, 1998, 109-161; y L. J. Rupp, “The future of women's history: feminism's history”, Journal of Women's history, 2, 2004, 9-29.

12. Los estudios sobre la delincuencia están gozando de una época dorada en la historiografía. Véase, M.L. Argot y C. Usborne (Eds.), Gender and crime in modern Europe, London, 1999. 
no-manchegas. También hubo un tipo de protesta y rechazo popular al orden establecido informal y más individual que se puede apreciar a través del análisis de las fuentes judiciales ${ }^{13}$.

Las estadísticas elaboradas por la administración de justicia en materia criminal entre 1883 y 1918 detectan que en Castilla-La Mancha la trasgresión de la ley fue un fenómeno estructural y permanente a lo largo de los años. La delincuencia tuvo un carácter más o menos estable, constante y regular. Las faltas, esto es, las prácticas sometidas a un castigo más leve, fueron las más abundantes $(75,45 \%)$. Los delitos, con penas más graves, sólo sumaron un $24,55 \%$ del total de las acciones encausadas por la justicia en las provincias que hoy conforman Castilla-La Mancha, porcentaje superior al de España (20,56 \%).

\section{MAPA No 1: Delitos juzgados en España, 1905-1914}

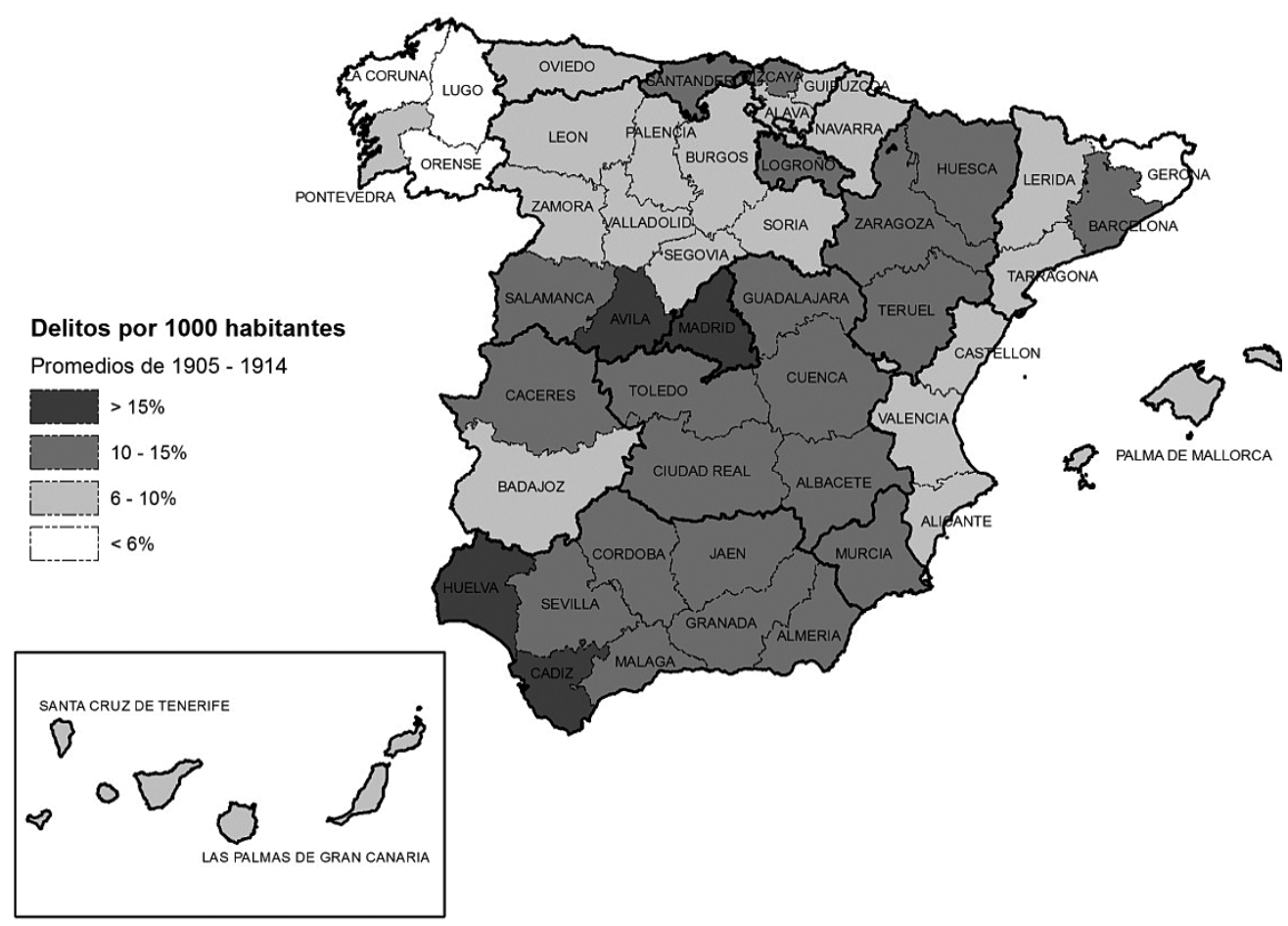

Fuente: Estadística de la Administración de Justicia en lo Criminal. Madrid, Ministerio de Gracia y Justicia.

13. La justicia como instrumento de control social la aborda Scott desde la perspectiva de las resistencias cotidianas en las sociedades rurales ante los sistemas de dominación. Nos revela otro modo de concebir el delito, presentándolo como estrategia de contestación a un poder que los ha excluido. De esta forma, el delincuente es antes un desposeído, un marginado (J. Scott, Los dominados y el arte de la resistencia, México, 2000). 
Según la Estadística de la Administración de Justicia en lo Criminal, entre los años de 1883 y 1918 las infracciones contra la propiedad fueron las más abundantes, representando el 39,87 \% de los delitos y el 53,55 \% de las faltas juzgadas en Castilla-La Mancha; esto es, algo más de 22.000 delitos y de 92.000 faltas. Estas mismas estadísticas ponen de manifiesto que los delitos contra la propiedad respecto al número de habitantes fueron superiores a la media nacional. Mientras la proporción de delitos y faltas contra la propiedad por cada mil habitantes en toda España era de 0,48 y 1,92 respectivamente, en Castilla-La Mancha el promedio se elevaba a 0,52 y 2,21 , tal vez por el mayor índice de pobreza del territorio con respecto a la media del país.

La infracción contra la propiedad más constante y castigada fue el hurto en todas sus provincias (67,54 \% de todos los delitos juzgados contra la propiedad en la región). De ellos, la mayoría lo fue a partir de la extinción o desarticulación de los antiguos espacios de uso y aprovechamiento común, libre o gratuito o en condiciones ventajosas, como puede apreciarse por la importancia que tuvieron las prácticas furtivas en los montes y campos de cultivo. El mayor porcentaje (24,44 \%) de las sentencias recayeron por hurto de leña; seguía con el 17,07 $\%$ el hurto de productos agroalimentarios y el $13,03 \%$ de ganado y aves ${ }^{14}$.

La protesta y resistencia ante la desposesión de los usos y aprovechamientos comunales tuvo su origen en la desamortización de Madoz iniciada en 1855, que supuso la enajenación del $14 \%$ de la superficie regional, especialmente en las provincias de Toledo y Ciudad Real. También tuvo su reflejo en la desaparición de los montes públicos. Provincias como las de Ciudad Real, que en 1859 tenía el 30 \% de su superficie de monte público, en 1926 apenas conservaba el $4 \%$. Toledo y Cuenca pasaron del $26 \%$ al 5 y el $10 \%$ respectivamente $^{15}$. La presencia de comunales y bienes municipales en la comunidad permitía que los campesinos pudiesen emplear una capacidad de trabajo excedente para obtener unos ingresos o beneficios complementarios con cultivos, ganado, caza, obtención de combustibles...

Estas prácticas punitivas contra la propiedad no sólo pueden explicarse a raíz del hambre. También eran muestra de un malestar social o resistencia a los cambios que estaban transformando el modo de vivir y relacionarse en la comunidad campesina. En el fondo del delito, en muchos casos había un «justificado» ataque contra la propiedad y lo que se consideraba por muchos injusta distribución de la misma y de la riqueza, que las desamortizaciones no sólo no habían corregido sino que la habían acentuado vendiendo las tierras subastadas a la burguesía, especialmente madrileña, y a la oligarquía terrateniente local, como han mostrado algunas investigaciones rigurosas sobre la provincia de Ciudad Real ${ }^{16}$.

14. Ó. Bascuñán Añover, Protesta y supervivencia. Movilización y desorden en una sociedad rural. CastillaLa Mancha, 1875-1923, Valencia, 2008, 235-244.

15. Grupo de Estudios de Historia Rural, "Más allá de la propiedad perfecta. El proceso de privatización de los montes públicos españoles (1859-1926)”, Noticiario de Historia Agraria, 8, 1994, 99-152.

16. Á.R. del Valle Calzado, Desamortización y cambio social en La Mancha (1836-1854), Ciudad Real, 1996; La desamortización de Madoz en la provincia de Ciudad Real, Ciudad Real, 1997; El liberalismo en el campo. Desamortización y capitalismo agrario en la provincia de Ciudad Real, 1855-1910, Ciudad Real, 2014, y El poder de la propiedad. Elites y desamortización en la España interior (Madrid y Castilla-La Mancha), Toledo, 2015. 
Las penas impuestas por la justicia eran desproporcionadas al bien sustraído, quizá por querer mostrarse de forma ejemplarizante como forma más eficaz para disminuir los delitos que la propia acción policial ${ }^{17}$. Por ejemplo, a finales del siglo XIX dos jóvenes de 14 y 16 años entraron en una viña del término de Almagro y sustrajeron 10 arrobas y 14 libras de uvas, valoradas en 6,30 pesetas. Por sentencia de 1895 fueron condenados a pagar $130 \mathrm{y}$ 125 pesetas de multa cada uno, librándose de la cárcel por la atenuante de la edad. Se trataba de una estrategia familiar de uso frecuente, propiciar que fueran los menores de edad los que delinquieran para evitar la cárcel de los mayores ${ }^{18}$.

Para el estudio de los delitos de las mujeres contra la propiedad ha sido preciso investigar las causas judiciales a través de los Libros de Sentencias de las Audiencias Provinciales, en los que se percibe una imagen más cercana de la realidad que la que ofrecen las estadísticas, una visión de una sociedad compleja y contradictoria, al margen de la ofrecida por los jueces, que permite comprender la situación social en la que se desenvolvían unas ciudadanas que no se resignaban a ser sujetos pasivos o silenciosos del cambio social. La investigación empírica se ciñe al estudio de 94 poblaciones repartidas entre las provincias de Albacete, Ciudad Real, Cuenca y Toledo entre 1890 y 1923. Un total de 2.281 expedientes judiciales y 3.338 procesados, de los que se va a extraer únicamente las causas protagonizadas por mujeres ${ }^{19}$.

El estudio sociológico de las procesadas descifra una procedencia social prácticamente homogénea que les vincula a los sectores más desfavorecidos de la sociedad, que, por otro lado, eran una amplia mayoría. No son grupos o sectores de población excluidos, alejados o escondidos de la sociedad que rozan la delincuencia profesional o la imagen más tópica que tenemos del bandolero, al contrario, eran mujeres que conformaban unidades domésticas dentro de cada comunidad campesina, madres, esposas e hijas cuyo fin principal en la vida pasaba por la reproducción y supervivencia del núcleo familiar. Más que una ambición, una necesidad que les arrastraba a vivir al borde de la legalidad, entre la insurrección pública y la obediencia sumisa. La delincuencia en estas décadas de cambios en el mundo rural ocultaba una situación de malestar social y conflicto maquillado por la deferencia simulada al cacique local ${ }^{20}$.

Pero antes de intentar definir el rostro de las imputadas por la justicia liberal, debemos preguntarnos cuántas eran y, sobre todo, respecto a la delincuencia masculina. Aunque la documentación examinada habla de procesadas y no de delincuentes exclusivamente, el por-

17. Como venganza, en algunas ocasiones se produjeron represalias contra los jueces. Al juez municipal de Tarazona de la Mancha (Albacete) le destrozaron en 1900 unas mil cien cepas y cortaron dieciséis olivos de una viña (Heraldo de Albacete, 5 de junio de 1900, "Daños").

18. Audiencia Provincial de Ciudad Real, Libro de Sentencias, año 1895, Sentencia número 90.

19. Ó. Bascuñán Añover, Protesta y supervivencia. Las prácticas populares del desorden en Castilla-La Mancha, 1875-1923, Tesis doctoral, dirigida por Francisco Alía Miranda, presentada en la Facultad de Letras de la Universidad de Castilla-La Mancha en 2006.

20. Véase M. Cabo y X. Veiga: "La politización del campesinado en la época de la Restauración. Una perspectiva europea”, en T. M. Ortega López y F. Cobo Romero (Eds.), La España rural, siglos XIX y XX. Aspectos políticos, sociales y culturales, Granada, 2011, 21-58; y N. Ortiz Albear, "Trabajos, salarios y movimientos sociales de las mujeres en la Restauración”, en J. Cuesta Bustillo (Dir.), Historia de las mujeres en España. Siglo XX, Madrid, 2003, Tomo I, 257-322. 
centaje de mujeres asciende al 8,83\%. Esto es, de un conjunto de 3.338 procesados obtenidos de la investigación empírica, 295 eran mujeres. Este baile de cifras y relaciones tan dado y, por otro lado, necesario para la historia de las relaciones de género, conlleva, sin embargo, un gran riesgo, enturbiar la comprensión de la realidad que se esconde tras la delincuencia. En efecto, aunque la relación es significativa, no podemos aseverar que ésta era una práctica de hombres, pues no se trataba de acciones individuales o espontáneas sino planificadas e incitadas en el seno familiar, donde las mujeres como administradoras de los bienes y recursos del hogar tenían una doble responsabilidad y cierta autoridad para inducir o enviar a los hombres a por combustibles o alimentos furtivos, también para solventar una afrenta.

Más del $80 \%$ de las mujeres imputadas se dedicaban a las labores del hogar, esto es, eran amas de casa, actividad que el argot judicial de la época denominaba como «labores de su sexo», lo que no les eximía de desempeñar otro tipo de tareas extra domésticas en momentos concretos. Mujeres que se encargaban de la administración de los alimentos dentro del hogar y que en momentos de necesidad se dedicaban a la rebusca de granos y cosechas, aunque estuviese prohibido, o hurtaban leña, frutos, gallinas u otro tipo de recursos necesarios para el mantenimiento de su prole.

En este caso, parece que la mujer asumía una serie de deberes y responsabilidades vitales para la reproducción de las economías campesinas, reconocidos por toda la comunidad. La principal tarea de éstas residía en garantizar la supervivencia de los suyos, por tanto, el respeto y la autoridad de la mujer se instalaba en el ámbito doméstico. Ellas administraban los recursos económicos familiares, alimentos, provisiones y combustibles. También trabajaban fuera del hogar, en épocas de siega y recolección, sirviendo en casa de familias acomodadas, lavando ropa, cuidando a niños o vendiendo en los mercados. El sistema legal de dominación sobre el género femenino que se erigía durante estas décadas las apartaba del ámbito público y la política ${ }^{21}$. No obstante, en numerosas ocasiones en las que de alguna manera se impedía o dificultaba su tarea principal, harían gala de lo que T. Kaplan denominó como «conciencia femenina $»^{22}$. Una identidad cultural que no sólo les conduciría a la protesta pública y política, en grupo, también parece que a muchas de ellas les llevó a vulnerar las leyes e infringir las normas a través de acciones delictivas, perseguidas y penadas por la justicia. Una serie de prácticas encaminadas al cumplimiento de un deber que la comunidad había otorgado a las mismas mujeres dedicadas al hogar: El sustento del grupo familiar.

Parece que todas las procesadas tenían algo en común. Ninguna de ellas era propietaria, su definición profesional también así lo revela. Su subalternidad se descubre por la escasez

21. La teoría de la complementariedad en L. Tilly y J. Scott, Women, work and family, Holt, 1978; A. Farge, "La historia de las mujeres. Cultura y poder de las mujeres: ensayo de historiografía", Historia Social, 9, 1991, 79-101. Sobre la construcción de la subalternidad de género, en M. Nash, Mujeres en el mundo. Historia, retos y movimientos, Madrid, 2004; y de la misma, "El mundo de las trabajadoras: identidades, culturas de género y espacios de actuación”, en J. Paniagua, J.A. Piqueras y V. Sanz (Eds.), Cultura social y política en el mundo del trabajo, Valencia, 1999.

22. T. Kaplan, “Conciencia femenina y acción colectiva: el caso de Barcelona, 1910-1918”, en J.M. Amelang y M. Nash (Eds.), Historia y género: las mujeres en la Europa moderna y contemporánea, Valencia, 1990, 267295. 
de recursos con los que garantizar la supervivencia, poco más que el que otorgaba su fuerza de trabajo y el de sus familias. Además, podemos añadir que el $92,88 \%$ de estas mujeres no tenían antecedentes penales, no eran lo que se puede clasificar como delincuente común. No delinquían como actividad habitual y exclusiva, sino que lo hacían fundamentalmente para complementar sus deterioradas economías. También sabemos que el 54,57 \% estaban casadas, esto es, se les supone una responsabilidad añadida por su condición de esposa y, posiblemente, de madre, el de poder ofrecer cada día un plato de comida a sus maridos e hijos. Lo cual no quiere decir que las solteras $(35,2 \%)$ y, sobre todo, las viudas $(9,8 \%)$ se encontrasen libradas de esta responsabilidad. Por tanto, nos queda indagar en las distintas formas en las que este grupo de mujeres infringió las leyes y mostró su disconformidad con el orden social que les relegaba a una situación de inferioridad. Una labor que pasa por descubrir las enormes fatigas en las que se desenvolvían las clases populares de estas décadas y el grado de insubordinación que estaban dispuestas a asumir en contra de la autoridad del Estado.

Los delitos contra la propiedad constituyen una amplia mayoría en el marco de las prácticas delincuenciales en estas décadas. Una acción que corresponde con la imagen que se tenía de las mujeres hurtadoras. En efecto, el hurto fue el auténtico protagonista dentro de los delitos contra la propiedad, donde también cabían los robos y las estafas. Nada especial que les distinga de las acciones de los hombres, salvo que el porcentaje de hurtos, y en su conjunto, contra la propiedad, fue más elevado en las mujeres. No en vano, la defensa de la propiedad privada constituía el eje de la justicia contra las clases subalternas, pues era en la propiedad donde se materializaban las estructuras de poder y las desigualdades que asfixiaban las condiciones de vida de los más necesitados. Estas prácticas expresaban resistencia y oposición al proceso de afianzamiento de la propiedad, pero también una insubordinación a las leyes y a la moral sancionada por la iglesia católica que tan repetida y cotidianamente predicaba en cada pueblo el «séptimo mandamiento». Unas acciones, por lo general, de escaso valor que buscaban el complemento necesario para la supervivencia de la unidad familiar, a pesar de que los jueces en su jerga las definieran «con ánimo de lucro», como si tales fueran para enriquecerse y no sencillamente para vivir.

En realidad, muchas de estas prácticas no suponían una novedad en las costumbres de las comunidades campesinas. No es necesario detenernos en los efectos del triunfo de la lógica capitalista en el campo, ni en el proceso de desarticulación de los terrenos comunales que restringía los tradicionales derechos de los vecinos a utilizar los comunales. Estos, que durante tanto tiempo habían actuado como «auténticas instituciones de beneficencia» para amortiguar los efectos de la pobreza, pasaron a convertirse en dominio privado, y, por tanto, quedaban vedados al aprovechamiento libre de los campesinos. Los campos se llenaron de guardas jurados al servicio de los nuevos propietarios con el fin de evitar determinadas acciones dentro de sus fincas, ahora privadas y protegidas por la ley. Las economías campesinas más débiles quedaban abandonadas a las necesidades del mercado de trabajo y a las nuevas relaciones de producción, pero ciertas prácticas como el pastoreo, la caza, la recolección de frutos o la apropiación de combustibles, materiales de construcción y fertilizantes en los an- 
tiguos montes no desaparecieron repentinamente. A pesar de ser perseguidas y penadas, prevalecieron en los hábitos, normas y costumbres de estas comunidades por algún tiempo ${ }^{23}$.

A pesar de que muchas de estas infracciones tenían un carácter muy leve, el poder judicial actuó con severidad y rigidez al imponer las penas, sobre todo si el delito había violado la propiedad privada, el derecho más protegido por el orden liberal. Así, el 63,05\% de las mujeres procesadas por cualquiera de estas causas fueron condenadas a cumplir alguna pena, porcentaje que ascendía al $65 \%$ en el caso de los delitos contra la propiedad. El castigo impuesto se explica ya dentro de las claves de una sociedad contractual y capitalista, la privación de libertad y la sanción económica conformaban el principio común que reunía a toda una gran diversidad de penas. En concreto, el 67,74\% de las mujeres condenadas fueron obligadas a cumplir una pena de arresto mayor y el $20,43 \%$ a tan sólo una multa económica, aunque ésta se traduciría en prisión subsidiaria por su condición de insolventes. Estas penas, no obstante, parecen desproporcionadas en relación al delito. Ahora bien, se aprecia menor dureza en los castigos impuestos a las mujeres, los porcentajes se elevan al 68,54\% de condenados y al 73,39\% en las causas contra la propiedad cuando sumamos los números de los hombres procesados. La responsabilidad moral de proveer el cuidado y sustento familiar podría explicar esta mayor indulgencia con las mujeres ${ }^{24}$.

\section{La delincuencia femenina en la posguerra (1939-1949): los delitos contra la propiedad}

«El descontento crece y se asemeja a los tiempos de Negrín», afirmaba en mayo de 1939 el cónsul francés en Barcelona ante el hambre y la miseria que veía en una ciudad arrasada durante la guerra civil. El cónsul de Francia en Málaga escribía a su ministro alertando sobre el descontento popular existente en esta ciudad a finales de 1939 por la falta de la mayor parte de productos básicos, incluido el pan, que constituía la base de la alimentación, lo que venía provocando tumultos y protestas de las mujeres ante los establecimientos, muchas de las cuales acababan en la cárcel. El pueblo culpaba al régimen en el poder. Tras ocho meses desde el final de la guerra no había tomado medidas para garantizar el abastecimiento de la población, sobre todo de pan. Se le reprochaba haber vaciado las despensas de España para dárselo a Alemania. Mucha gente, sobre todo aquella menos comprometida desde el punto de vista ideológico, se preguntaba para qué había servido la guerra, pues ahora eran más pobres. Nunca antes el pueblo había sido tan desgraciado, tan pobre y tan desprovisto como ahora. Para el cónsul, sólo su apatía, indolencia, pasividad e increíble sobriedad le permite soportar

23. Los efectos de la llamada desarticulación de los bienes comunales en A. Sabio Alcutén, "Imágenes del monte público, patriotismo forestal español y resistencias campesinas, 1855-1930", Ayer, 46, 2002, 123-153; y en J.A. Piqueras (Coord.), Bienes comunales: propiedad, arraigo y apropiación, Madrid, 2002.

24. Sobre las instituciones punitivas y el derecho penal como elemento de control social del delito y la pobreza ha dedicado numerosas obras R. Bergalli, desde obras ya clásicas, El pensamiento criminológico. Un análisis crítico, Barcelona, 1983; a otras más reciente, "Las estrategias de control social y la violencia del sistema penal", Sistema, 132-133, 129-143; y Sistema penal y problemas sociales, Valencia, 2003. 
la situación, pero todo tiene un límite: «si se prolonga la falta de alimentos especialmente de pan podrían venir problemas más serios» ${ }^{25}$.

Tampoco faltaban las voces de algunas de las autoridades del régimen clamando contra el hambre de la mayor parte de la población, aunque se limitaban a hacerlo por escrito a sus superiores jerárquicos o a la Comisaría General de Abastecimientos ${ }^{26}$. El gobernador civil de Alicante, por ejemplo, se refirió al problema de las subsistencias en los siguientes términos: «La situación en la provincia es pavorosa, prácticamente en la Provincia seríamos todos cadáveres si tuviéramos que comer de los racionamientos de la Delegación de Abastecimientos» ${ }^{27}$. El gobernador de Huelva lo hacía en términos similares: «De no ser resuelta esta situación insostenible con la urgencia y premura que exigen las circunstancias, los 375.000 españoles que habitan esta Provincia caerán en el mayor desamparo y la más trágica desesperación, puesto que se verán condenados al hambre por falta de pan, y a la miseria por la muerte de sus ganados y la imposibilidad de sembrar y de adquirir lo más perentorio para la satisfacción de sus necesidades ${ }^{28}$.

Un informe del Auxilio Social de la provincia de Ciudad Real en el otoño de 1940 decía: «los abastos son malos, falta totalmente el azúcar, en muchos pueblos ha faltado y falta el pan; en Daimiel han estado sin él un mes seguido; (...) el número de necesitados se eleva a más de 35.000, habiendo comarcas como la de Alcázar, Manzanares, Puertollano e Infantes donde la población siente verdadera hambre, sin encontrar medios con qué aplacarla. Se avecina un invierno difícil a causa de la pérdida de la cosecha de uva, principal riqueza de esta provincia» ${ }^{29}$.

Alan Hillgarth, comandante de la Royal Navy británica, veía claros síntomas de descontento social provocado por el hambre y la desesperación en noviembre de 1939: «El des-

25. Francisco Alía Miranda: "La España que vio el embajador Pétain: Hambre y descontento social en 1939”, Historia Social, 82, 2015, 73-91.

26. Los informes oficiales de algunos gobernadores, policías, autoridades locales y provinciales, etc., mostraban a veces la preocupación de las autoridades franquistas por uno de los problemas más graves del régimen, el de la falta de abastecimientos, que estaba provocando el rechazo de buena parte de la población, como ponen de manifiesto C. Molinero y P. Ysàs, "El malestar popular por las condiciones de vida. ¿Un problema político para el régimen franquista?”, Ayer, 52, 2003, 255-280. También: F. Cobo Romero y T. Ortega López, "Hambre, desempleo y emigración. Las consecuencias sociales de la política agraria autárquica en Andalucía oriental, 1939-1975”, Hispania, LXIV/3, 2004, 1.079-1.112; D. Ginard i Ferón, "Las condiciones de vida durante el primer franquismo. El caso de las Islas Baleares", Hispania, 212, 2002, 1.0991.128; C. Molinero y P. Ysàs, Patria, Justicia y Pan. Nivel de vida i condicions de treball a Catalunya, 19391951, Barcelona, 1985; T. M. Ortega López, Del silencio a la protesta. Explotación, pobreza y conflictividad en una provincia andaluza, Granada 1936-1977, Granada, 2003; y J. Serrallonga, "Subordinación, abastos y mortalidad. La Montaña catalana, 1939-1945”, Historia Social, 34, 1999, 45-66.

27. D. Sanz Alberola, La implantación del franquismo en Alicante. El papel del Gobierno Civil (1939-1946), Alicante, 1999, 155.

28. J. I. González Orta, "La gestión del hambre. Discurso y praxis política de la Falange en la Huelva de la posguerra (1939-1945)”, Erebea. Revista de Humanidades y Ciencias Sociales, 2, 2012, 396.

29. E. Muñoz Sánchez, "La Sección Femenina en Castilla-La Mancha”, en M. Requena Gallego (Coord.), Castilla-La Mancha en el franquismo, Ciudad Real, 2003, 144. 
contento se está extendiendo por todas partes. La falta de comida, su coste cuando está disponible y la mala distribución de los alimentos disponibles están colocando a la gente en un estado cercano a la desesperación. Un cuarto de la población de España está prácticamente muriéndose de hambre». La situación era límite; tanto que se auguraban disturbios en las grandes ciudades si la situación no cambiaba ${ }^{30}$.

La situación no fue mejorando en los años posteriores, para muchos historiadores de la economía por los efectos perversos de la autarquía, la política económica intervencionista del régimen ${ }^{31}$. El riguroso control de la producción y la distribución de productos básicos provocaron el establecimiento del racionamiento, aunque no adquirió cierta regularidad hasta 1943, y el nacimiento del mercado negro en el que los precios, dependiendo del producto, podían estar entre dos y siete veces por encima del oficial. El Producto Interior Bruto (PIB) de 1935 no volvió a ser alcanzado hasta 1951 mientras que el nivel de renta per cápita tardaría dos años más: «Fue así como la dictadura empujó a la ilegalidad a gran parte de la población que si, en el plano político, adoptó actitudes pasivas, en el ámbito de la subsistencia cotidiana convirtió, y percibió, la transgresión de la ley en algo común y aceptado» ${ }^{32}$.

La preocupación principal del momento era la económica. Combatir el hambre fue la única ocupación de niños, mujeres y hombres que poblaban cualquier parte del país. Sobrevivir, lamentarse y olvidar era el trinomio perfecto, buscado de propósito por el régimen para desmovilizar el cuerpo social ${ }^{33}$. El miedo y la represión generaron un «desinterés» de la mayoría hacia los asuntos públicos, volcándose casi todos hacia un único objetivo: la supervivencia. El hambre, la arbitrariedad y la corrupción casi generalizada provocaron que todos, o casi todos, distrajeran recursos o lo intentaran, desde las clases altas a las bajas. Pero a unos

30. M. Á. del Arco Blanco, "Morir de hambre. Autarquía, escasez y enfermedad en la España del primer franquismo", Pasado y Memoria. Revista de Historia Contemporánea, 5, 2006, 248.

31. C. Barciela, "La Economía y la Guerra", Pasado y Memoria. Revista de Historia Contemporánea, 8, 2009, 25-27. Del mismo autor: "La España del estraperlo", en J. L. García Delgado, El primer franquismo. España durante la Segunda Guerra Mundial, Madrid, 1989; "Autarquía y mercado negro. La auténtica economía política del franquismo", en Ángel Viñas (Ed.), En el combate por la Historia. La República, la guerra civil, el franquismo, Barcelona, 2012, 645-658; C. Barciela y M. I. López Ortiz, "El fracaso de la política agraria del primer franquismo, 1939-1959. Veinte años perdidos para la agricultura española”, en C. Barciela (Ed.), Autarquía y mercado negro. El fracaso económico del primer franquismo, 1939-1959, Barcelona, 2003; y "Franquismo y corrupción económica”, Historia Social, 30, 1998, 83-96. De semejante opinión pueden verse, entre otros: P. Martín Aceña, "La economía de la guerra civil: perspectiva general y comparada”, en P. Martín Aceña y E. Martínez Ruiz (Eds.), La Economía de la Guerra Civil, Madrid, 2006, 50-51; A. Carreras, "La producción industrial española, 1842-1981: construcción de un índice anual", Revista de Historia Económica, año II, 1, 1984; y F. Comín y P. Martín Aceña, "La política autárquica y el INI”, en G. Sánchez Recio y J. Tascón (Eds.), Los empresarios de Franco. Política y economía en España, 19361957, Barcelona, 2003.

32. Ó. Rodríguez Barreira, "Lazarillos del caudillo. El hurto como arma de los débiles frente a la autarquía franquista”, Historia Social, 72, 2012, 68-69.

33. Richard, op. cit., 168. 
se les persiguió y castigó sistemáticamente, a otros se les permitió hasta cierto punto y a unos pocos se les dio total impunidad ${ }^{34}$.

El ambiente hostil hacia la política económica y, sobre todo, la propia situación de extrema necesidad facilitó que los delitos contra la propiedad crecieran por todos los rincones del país, bastante más que en tiempos anteriores a la guerra. Para Rodríguez Barreira ${ }^{35}$, el número de delitos contra la propiedad en España que llegaron a los Juzgados de Instrucción de las Audiencias Provinciales muestran un importante incremento entre 1940 y 1951 con respecto al período 1915-1936. Antes de la guerra, la media de los delitos anuales oscilaba entre 30.000 y 40.000. En la posguerra los delitos se sitúan en cifras medias entre los 55.000 $\mathrm{y}$ los 79.000 .

En los territorios estudiados hasta ahora puede percibirse la importancia de estos delitos comunes en relación al resto. En Murcia representaban en torno al $60 \%$, aunque en los años 1941-1942 se supera ampliamente llegando al $64 \%$. En Lleida y Girona se situaban entre el 55 y el $60 \%$, mientras Tarragona y Barcelona alcanzaban el $70 \%$. En Albacete se llegaba al $69 \%$ y en Almería el 49,29\%, el porcentaje más bajo de todos los conocidos ${ }^{36}$. Según las estadísticas oficiales, la media nacional de los delitos contra la propiedad se situaba en el 52,20 $\%$ de todos los delitos comunes en 1943 y en el $56,85 \%$ en $1949^{37}$.

La respuesta de muchos hombres y mujeres ante el hambre fue la misma, sobrevivir, pero las estrategias fueron diversas. Los hombres solían callar mientras que muchas mujeres encontraron una vía en algunas tímidas protestas en la calle o en las infracciones contra la propiedad. El reparto de «funciones» se explica principalmente por la dureza en la represión, más evidente en el género masculino que en el femenino, como venía siendo habitual desde los años de la guerra. Recordemos que de los 150.000 ejecutados por el franquismo durante la guerra y posguerra, según las cifras estimadas por algunos de los estudios más rigurosos ${ }^{38}$, las mujeres no superaron el 9,5\% de todos los muertos provocados directa o indirectamente por la guerra.

Para la mayor parte de hombres, las expectativas que ofrecía una postura de oposición política (como era calificada cualquier tipo de protesta pública) en la posguerra eran pocas y peligrosas, hasta el punto que se pueden definir en dos: cárcel y muerte. A pocos les merecía la pena el riesgo de sufrir la represión frente a la certeza de vivir en paz, por muy miserable que esta fuera ${ }^{39}$. El silencio y la pasividad de los trabajadores en el primer franquismo «no era equivalente a la aceptación del régimen sino, sobre todo, producto del miedo y de la

34. C. Mir Curcó: op. cit.; y Ó. J. Rodríguez Barreira: op. cit.

35. Rodríguez Barreira, loc. cit., 70-71. Basa su información en los Anuarios Estadísticos del INE.

36. Rodríguez Barreira, op. cit., 170-171.

37. Elaboración propia a partir de las tablas de población reclusa de las prisiones centrales y provinciales penada en $1^{\circ}$ de enero de 1943 y de 1949 publicadas en los Anuarios Estadísticos de España del Instituto Nacional de Estadística de 1944-1945 y de 1949.

38. S. Juliá (Coord.), Víctimas de la guerra civil, Madrid, 1999.

39. A. Cazorla Sánchez, "Sobre el primer franquismo y la extensión de su apoyo popular", Historia y política: Ideas, procesos y movimientos sociales, 8, 2002, 316. 
percepción de indefensión $»^{40}$. Otros callaban simplemente porque esperaban el favor de las nuevas autoridades tanto en el mercado negro como en el laboral ${ }^{41}$. Se creó así «un complejo entramado de intereses en los que la política del favor y el aprovechamiento fraudulento de los puestos en la administración fueron moneda de uso corriente» ${ }^{42}$.

El descontento era un hecho. Pero el estrecho control social y el miedo a perder la vida o los alimentos impidieron cualquier tipo de manifestación abierta y colectiva, una oposición «desde abajo» al régimen. La Falange se convirtió en el mejor paraguas protector que tuvo Franco para evitar unas críticas que de otro modo nunca las habría podido esquivar $^{43}$. El malestar de numerosas personas pertenecientes a las clases más modestas pasó fundamentalmente por una resistencia silenciosa frente a la política autárquica, entrando a participar en el mercado negro y adoptando otra serie de prácticas que posibilitasen su supervivencia. Así la estabilidad del régimen estaba garantizada: «De este modo, y de forma paradójica, las críticas condiciones socio-económicas vividas durante el primer franquismo, fueron un elemento más que contribuyeron a la solidez y continuidad del régimen franquista», escribe Arco Blanco ${ }^{44}$.

Las mujeres protagonizaron las pocas manifestaciones públicas que hubo contra la política económica del régimen, en muchos casos por la propia desesperación ante el hambre. Algunas no pudieron aguantar más y se quejaron públicamente en las colas y en las tiendas tanto de la falta de suministros básicos como de la salida de algunos de ellos para Alemania e Italia, como pago a las deudas contraídas durante la guerra, aunque en muchas de ellas tras la necesidad económica se podía apreciar una reivindicación política, una «rebeldía cotidiana» contra el régimen ${ }^{45}$. Los diplomáticos franceses tampoco entendían por qué las importa-

40. C. Molinero y P. Ysàs, "La historia social de la época franquista. Una aproximación”, Historia Social, 30, 1998, 149.

41. El marco laboral fue uno de los instrumentos de represión más efectivos de la dictadura, pues su asfixiante maquinaria legal ejerció a la perfección su papel de someter a los trabajadores y de condicionar sus hábitos de vida, según M. Vilar Rodríguez, "Estrategias de supervivencia de las familias trabajadoras en el mercado laboral hostil de la posguerra civil española (1939-1958)", Sociología del trabajo, 56, 2006, 119-154.

42. Ó. J. Rodríguez Barreira y A. Cazorla Sánchez: “Hoy Azaña, mañana... Franco. Una microhistoria de caciquismo en democracia y dictadura. Berja (Almería), 1931-1945)”, Hispania, 229, 2008, 501.

43. J. A. Parejo Fernández, "El sermón antifalangista en los años del hambre”, Farua: revista del Centro Virgitano de Estudios Históricos, 8, 2005, 143-161.

44. Arco Blanco, loc. cit., 257-258. Sobre las actitudes de protesta o resistencia pueden verse, además, C. Hernández Burgos, Franquismo a ras de suelo: zonas grises, apoyos sociales y actitudes durante la dictadura (1936-1976), Granada, 2013; Ó. J. Rodríguez Barreira, op. cit.; y Ó. J. Rodríguez Barreira (Ed.), El franquismo desde los márgenes: campesinos, delatores, mujeres, menores, Lleida, 2013.

45. C. Cabrero Blanco, "Espacios femeninos de lucha. Rebeldías cotidianas y otras formas de resistencia de las mujeres durante el primer franquismo", Historia del Presente, 4, 2004, 31-46. Para esta autora, además, las mujeres de presos mostraron cada día en el exterior de las cárceles su «rebeldía cotidiana», su oposición al régimen, como una modalidad de resistencia antifranquista específicamente femenina. Sobre esta misma idea, G. Di Febo, Resistencia y movimiento de mujeres en España, Barcelona, 1979; M. Yusta, "Rebeldía individual, compromiso familiar, acción colectiva. Las mujeres en la resistencia al franquismo durante los 
ciones estaban prácticamente suprimidas mientras se exportaban claramente productos de primera necesidad como harina y aceite a Alemania e Italia. El aceite era almacenado por las autoridades italianas y posteriormente revendido a España a buen precio y contra divisas ${ }^{46}$.

Tuvieron que pasar los años de las ejecuciones, de la omnipresente represión, para que pudieran verse algunas formas de protestas públicas y colectivas contra la miseria, como la «revuelta de hambre» en la localidad gallega de O Saviñao, en 1946, para evitar la salida del grano $^{47}$. Estas manifestaciones no eran nuevas. Recordaban a los motines populares de finales del siglo XIX y principios del XX, que la propia guerra había recuperado en el bando republicano, especialmente en las grandes ciudades ${ }^{48}$.

La presencia de las mujeres en la delincuencia cotidiana es mayor que en las instituciones de represión política. En Almería ${ }^{49}$, por ejemplo, de todos los procesados por hechos políticos por la justicia militar franquista, el $92,42 \%$ eran varones mientras que únicamente el $7,58 \%$ eran mujeres. A pesar de que comparativamente el número de mujeres detenidas por la Guardia Civil (2.838) fue sensiblemente inferior al de los hombres (13.137), el porcentaje de mujeres detenidas por la Guardia Civil (17,75\%) es muy superior al porcentaje de mujeres que pasaron por la justicia militar $(7,58 \%)$ y por el Tribunal de Responsabilidades Políticas (3,61 \%). Según las cifras del Instituto Nacional de Estadística, el 11,93 \% de los procesados por la Audiencia Provincial de Almería entre 1947 y 1950 eran mujeres mientras que el 88,07 $\%$ eran varones. Estos datos confirman la mayor presencia de las mujeres en la delincuencia cotidiana que en las instituciones de represión política. Si comparamos este dato con los que ofrece la justicia ordinaria en otras provincias del Estado la diferencia es menor. En Tarra-

años cuarenta", Historia del presente, 4, 2004, 36-93; I. Abad, En las puertas de prisión. De la solidaridad a la concienciación política de las mujeres de los presos del franquismo, Barcelona, 2012; y C. Cabrero, Mujeres contra el Franquismo (Asturias 1937-1952). Vida cotidiana, represión y resistencia, Oviedo, 2006.

46. Alía Miranda: loc. cit., 85. El embajador británico en España también mostró a su ministro meses después, el 1 de julio de 1940, la sorpresa que producía ante las siniestras perspectivas de provisiones de alimentos para afrontar el invierno que la totalidad de la cosecha de patatas de la zona de Valencia había sido enviada a Alemania. Tomates y frutas en grandes cantidades estaban de camino. La contribución de España a la causa alemana podía significar "casi la inanición de su pueblo" (Arco Blanco, loc. cit., 244). En Málaga, según testimonio de los habitantes más mayores, durante el desarrollo de la II Guerra Mundial salían del puerto bidones de aceite que llevaban un contradictorio rótulo: sobrante de España (Barranquero Texeira y Prieto Borrego, op. cit., 120).

47. M. J. Souto Blanco, “Una revuelta de hambre en la Galicia del Primer Franquismo: O Saviñao", Pasado y Memoria. Revista de Historia Contemporánea, 2, 2003, 241-254.

48. Por ejemplo, en Madrid, desde 1938 la gente ya no aguantaba más, por lo que se fueron generalizando las manifestaciones y tumultos por sus calles, en protesta por la penuria y calamidades de una guerra que consideraban ya inútil. Los manifestantes eran en su mayoría mujeres, en algunos casos organizados previamente por la organización clandestina de la Quinta Columna. Según testimonio de algún testigo, el grito más generalizado era el de: ¡Queremos pan y carbón, y si no: la rendición! (F. Alía Miranda: La agonía de la República. El último año de la guerra civil española, 19381939, Barcelona, 2015, 171). Para analizar la trayectoria histórica: V. Lucea Ayala, "Amotinadas: las mujeres en la protesta popular", Ayer, 47, 2002, 185-207.

49. Rodríguez Barreira, op. cit., 77 y 180. 
gona el 13,61 \% de los procesados entre 1939 y 1941 eran mujeres, mientras que en Lleida lo eran el 14,98\%. En Murcia sólo el 9,1 \% de los procesados eran de sexo femenino.

Los delitos que cometían las mujeres y los que practicaban los hombres generalmente eran similares, aunque con diferencias en los delitos por faltas morales. En Almería, las mujeres mantienen unos valores muy cercanos a los de los varones en los delitos económicos (56,41\%-59,49\%), políticos (7,68 \%-9,96\%) y penales (2,75\%-3,05\%), pero son detenidas en el doble de ocasiones por faltas morales. En los varones estas faltas únicamente representan el 8,53 \% del total mientras que en las mujeres éstas ocupan el 16,6\%. Dentro de los delitos económicos, los referidos a consumos y abastos serán cometidos en una proporción mayor por las mujeres $(55,65 \%)$ que por los hombres $(35,02 \%)$ poniéndose de manifiesto que la conciencia femenina impele a las mujeres «a desafiar la ley cuando estaba en juego la supervivencia económica de sus familias $»^{50}$.

Esta tendencia analizada exhaustivamente a nivel local puede corroborarse con las cifras de las estadísticas oficiales de la población reclusa en el conjunto de toda España durante los años de la posguerra, que muestran un incremento constante del porcentaje de mujeres con respecto a los hombres, sobre todo a partir de la finalización de la guerra. 1940 fue el año en el que más presas políticas hubo (unas 20.000); a partir de entonces se fueron reduciendo las penas por delitos políticos y fueron aumentando las de los delitos económicos.

TABLA No 1 : Población reclusa en $1^{\circ}$ de enero (Total y porcentaje)

\begin{tabular}{|l|l|l|l|}
\hline AÑO & HOMBRES & MUJERES & TOTAL \\
\hline 1930 & $8.524(93,1 \%)$ & $628(6,9 \%)$ & 9.152 \\
\hline 1931 & $9.800(94,4 \%)$ & $586(5,6 \%)$ & 10.386 \\
\hline 1932 & $5.942(94,9 \%)$ & $322(5,1 \%)$ & 6.264 \\
\hline 1933 & $8.271(95,7 \%)$ & $369(4,3 \%)$ & 8.640 \\
\hline 1934 & $12.087(96,1 \%)$ & $487(3,9 \%)$ & 12.574 \\
\hline $1939^{*}$ & $90.413(90,2 \%)$ & $9.849(9,8 \%)$ & 100.262 \\
\hline 1940 & $247.487(91,4 \%)$ & $23.232(8,6 \%)$ & 270.719 \\
\hline 1941 & $213.640(91,5 \%)$ & $19.733(8,5 \%)$ & 233.373 \\
\hline 1942 & $145.851(91,5 \%)$ & $13.541(8,5 \%)$ & 159.392 \\
\hline 1943 & $112.735(90.6 \%)$ & $11.688(9,4 \%)$ & 124.423 \\
\hline 1944 & $\ldots(\sin$ datos por sexo) & $\ldots(\sin$ datos por sexo) & 74.095 \\
\hline 1945 & $48.812(90,3 \%)$ & $5.260(9,7 \%)$ & 54.072 \\
\hline 1946 & $39.527(90,2 \%)$ & $4.285(9,8 \%)$ & 43.812 \\
\hline
\end{tabular}

50. Rodríguez Barreira, op. cit., 180-181. 


\begin{tabular}{|l|l|l|l|}
\hline 1947 & $32.380(89,0 \%)$ & $3.999(11,0 \%)$ & 36.379 \\
\hline 1948 & $34.141(89,5 \%)$ & $3.998(10,5 \%)$ & 38.139 \\
\hline 1949 & $33.524(89,5 \%)$ & $3.917(10,5 \%)$ & 37.451 \\
\hline
\end{tabular}

( ${ }^{*}$ En $1^{\circ}$ de abril). Fuente: Anuario Estadístico de España 1949. INE, Elaboración propia, p. 993.

Las mujeres «delincuentes» justifican el hurto por la miseria, como una mujer de Carboneras (Almería), que fue sorprendida por la Guardia Civil mientras recogía almendras de una propiedad ajena. Interrogada, resultó ser una viuda de 45 años con ocho hijos bajo su responsabilidad. Manifestó que ni los terrenos ni los almendros eran de su propiedad pero que si estaba recogiendo el fruto era por carecer de comida para atender a las necesidades de su extensa prole: «Alguna cosa tenían que comer», se defendía ante las autoridades. En calidad de madres, hermanas o esposas, las mujeres individualmente anteponen la defensa de la subsistencia de la familia a cualquier normativa pero el imaginario es compartido y amparado con la aquiescencia pasiva de la comunidad ${ }^{51}$.

El caso de Castilla-La Mancha lo hemos estudiado a partir de los Libros de Sentencias de las Audiencias Provinciales del período 1940-1949, que se encuentran depositados en los archivos de las Audiencias Provinciales de Albacete, Ciudad Real, Cuenca, Guadalajara y Toledo. El conjunto de los 56 libros contienen 9.642 sentencias $^{52}$. De estas, 2.180 (22,61 \%) tienen como protagonistas a mujeres, bien porque son juzgadas, bien como víctimas de un delito.

De las 2.180 sentencias con presencia de mujeres, 949 corresponden a causas por delitos contra la propiedad (43,53\%), principalmente por apoderamiento de víveres y ropa. Esto nos lleva a afirmar que, en las sentencias analizadas, los agrupados en esta categoría de delitos vieron en el hurto y el robo un medio para paliar las necesidades propias y de su familia, desesperadas por asegurar la supervivencia ${ }^{53}$.

En los 949 expedientes analizados en las Audiencias Provinciales de la región por los denominados «delitos contra la propiedad», encontramos un total de 1.927 personas juzgadas como autores o encubridores del hecho juzgado. De ellas, 1.236 son mujeres. En 574 casos $(60,48 \%)$ son respuestas exclusivas de mujeres, que sin la participación de hombres actúan individualmente para conjurar el hambre. La acción conjunta de mujeres y hombres se ve representada en 375 casos (39,52\%), en los que ambos adoptan una posición común

51. Rodríguez Barreira, loc. cit., 80-81 y op. cit. 195.

52. La investigación se desarrolló a partir de la tesis doctoral, dirigida por F. Alía Miranda, de H. Vicente Rodríguez-Borlado: Mujer en el primer franquismo. Itinerarios de vida. Castilla-La Mancha 1939-1949. Ciudad Real, Facultad de Letras de la Universidad de Castilla-La Mancha, 2012.

53. Seguían de lejos los clasificados como delitos sexuales (20,45\%), de los que la prostitución era el más importante. Era una muestra más del hambre y la miseria de buena parte de mujeres. El 19,47\% fueron sentencias contra la moral, buenas costumbres y violencia de género. Con el $9 \%$ aparecen abortos, infanticidios y abandono de menores y con el 4,9\% los delitos contra la autoridad. El resto se repartían entre coacciones, delitos contra la religión, falsa identidad, tenencia de armas, etc. 
frente al hambre y, en grupos numerosos o en parejas, intervienen sobre los recursos que tienen a su alcance y de los que carecen.

La necesidad compartida llevó a muchas mujeres a aunar esfuerzos cuando mayores posibilidades de éxito preveían, repartiéndose posteriormente el botín. Vecinas, amigas y paisanas actuaban conjuntamente. También es común ver a madres con hijos, pensando en el menor castigo hacia los menores de edad. El «robo en cuadrilla» se explica por la consecución de uno de los objetivos prioritarios que se ha asignado tradicionalmente al rol de la mujer como es el mantenimiento del hogar, lo que podríamos llamar como «buena gestión de la economía doméstica» ${ }^{54}$.

Un día antes de la Nochebuena de 1945, tres jóvenes se dirigen a la finca «El Retamar», de Argamasilla de Alba (Ciudad Real), y sustrajeron dos ovejas por 360 pesetas. Con ellas, fueron al domicilio de uno de ellos, donde junto con los otros cuatro procesados, «comieron entre todos la carne de las mismas y procedieron posteriormente a la venta de sus pieles» ${ }^{55}$. Entre los participantes estaban tres hermanos y su madre. El núcleo familiar, al que el franquismo otorgó un papel central en el entramado orgánico del Estado, servía para urdir las estrategias comunes de supervivencia que nada tenían que ver con las glorias que mujer, marido e hijos debían entonar armónica y sigilosamente para la construcción de la nueva patria.

Madre e hijo intervinieron en un robo en la localidad de Yeste (Albacete), según reza la sentencia la mujer indujo a su hijo y un amigo a entrar en un cortijo y llevarse comestibles y otros objetos ${ }^{56}$. En 1941, una mujer viuda en unión de su hijo, "penetraron en el interior de dicho domicilio y con ánimo de lucro se apoderaron de determinada cantidad de aceite, jamones, cereales, patatas y otros efectos... tasados en la cantidad de mil quinientas dieciséis pesetas» ${ }^{57}$.

La mayor parte de acciones delictivas contra la propiedad son robos y hurtos, que suman entre ambos 872 causas (91,88 \%). La preeminencia absoluta de los supuestos de hurto y robo nos vuelve a colocar en la relación entre hambre y miseria, con la utilización de recursos de carácter delictivo como una última oportunidad para sobrevivir. Persiguen con ellos obtener alimentos, ya sea de corrales, campos o vagones de tren, para consumirlos, en algunos casos, inmediatamente después, repitiéndose idénticas pautas de conducta en toda la región. Prácticamente en su totalidad se realizan sin ningún tipo de armas: «la violencia femenina es más bien ruido y furia» ${ }^{58}$.

En general, los hurtos y robos de baja cuantía, que en los dos primeros años de la década aparecen tímidamente, irrumpen con fuerza en el año 1942 mostrando un incremento considerable desde el año 1947, en el que los casos juzgados por esta razón llegan a 166. La política autárquica, lejos de resolver el problema, aseguraba la continuidad de la penuria, haciendo más difícil cada día la vida cotidiana.

54. M. Nash, Mujer, familia y trabajo en España, 1875-1936. Barcelona, 1983.

55. Audiencia Provincial de Ciudad Real, Libro de Sentencias, año 1949, Volumen II, Sentencia número 358.

56. Audiencia Provincial de Albacete, Libro de Sentencias, año 1943, Sentencia número 133.

57. Audiencia Provincial de Albacete, Libro de Sentencias, año 1946, Volumen I, Sentencia número 30.

58. N. Castan, "La Criminal", en G. Duby y M. Perrot, Historia de las mujeres, Vol. 3, Madrid, 2000, 517. 
La mayor parte de robos y hurtos eran simplemente para comer. En muchos casos justificaban el delito por la falta de trabajo del marido, como en el término de Navamorcuenda (Toledo), cuando un hombre y su mujer asaltan un corral y se apoderan de una cerda que trasladan hasta su domicilio, donde parte de la carne la consumieron entre los procesados y sus cinco hijos: «todos los procesados se hallaban acuciados por el hambre en el momento de ocurrir los hechos, por falta de medios de subsistencia debido a hallarse sin trabajo» ${ }^{59}$.

En otros las mujeres eran viudas de la guerra o de la represión de posguerra o sus maridos estaban en la cárcel, por lo que tuvieron que delinquir. Una sentencia dice que «se apoderaron de tres gallinas que llevaron a casa del procesado fallecido MRN y las guisó la esposa de este, también procesada, y se las comieron ${ }^{60}$. Una viuda de 39 años y conducta catalogada como «indefinida» se apropió en el pueblo de Munera (Albacete) de una cabra que «sacrificó en el acto, comiéndose la carne en unión de sus hijos menores...La procesada es una débil mental» ${ }^{61}$.

Muy aplaudidos por la gente, e incluso encubiertos popularmente, fueron los «robos sociales» contra las propiedades de las instituciones del nuevo régimen. La favorita fue el Servicio Nacional de Trigo, donde varios almacenes que tenía por sus pueblos fueron asaltados. En diciembre de 1945, tres hombres y una mujer de 57 años, madre de uno de los autores, «practicaron un orificio en una de las paredes del almacén que en Calzada de Calatrava tienen el Servicio Nacional de Trigo, y que constituye dependencia de casa habitada, sacando por dicho agujero en diversas ocasiones hasta un total de 20 fanegas de trigo». Fueron condenados a cuatro años de prisión y seis meses de arresto al menor de edad ${ }^{62}$. En Horcajo de Santiago, una mujer y un hombre "penetraron en el almacén que el Servicio Nacional del Trigo tiene instalado en dicho pueblo» y consiguieron apoderarse de la harina allí depositada. Ambos carecían de antecedentes penales y tenían buena conducta informada ${ }^{63}$.

El total de los procesos lo completan 34 casos de estafa, 18 de fraude en el fluido eléctrico y los 20 restantes dan cuenta de casos de apropiación indebida, daños, falsedad, alzamiento de bienes, usura, malversación y allanamiento.

Muchos de los casos de estafa hacían recordar la rica tradición de la picaresca española. Uno de los más curiosos sucedió en Villanueva de Alcardete (Toledo), «A. A. L. gozaba de fama de mantener comunicación con la Virgen y los Santos, y de conocer por este medio el paradero de los desaparecidos durante la pasada guerra, con cuyo motivo era muy visitada su casa». Prometiendo que iba a tener lugar un gran milagro y asegurando el regreso de todos los desaparecidos, consiguió que una mujer le entregara 2.000 pesetas, y después otras 3.000, porque «según la conversación que había mantenido con el difunto marido de la María, éste se encontraba bien y solicitaba que la María entregase 3.000 pesetas para una sepultura, y que

59. Audiencia Provincial de Toledo, Libro de Sentencias, año 1942, Sentencia número 103.

60. Audiencia Provincial de Ciudad Real, Libro de Sentencias, año 1942, Sentencia número 139.

61. Audiencia Provincial de Albacete, Libro de Sentencias, año 1943, Sentencia número 118.

62. Audiencia Provincial de Ciudad Real, Libro de Sentencias, año 1947, Volumen I, Sentencia número 103.

63. Audiencia Provincial de Cuenca, Libro de Sentencias, año 1948, Sentencia número 44. 
en caso contrario vendría un gran castigo». A otra mujer, cuyo hijo había desaparecido, le dijo que estaba bien y se había hecho fraile pidiéndole por encargo de él dinero para una virgen. Así fue repitiendo este tipo de engaños, hasta que la desconfianza generada en algunas de las víctimas la llevó ante los tribunales ${ }^{64}$.

La insolvencia identifica al colectivo social analizado en el conjunto de los delitos contra la propiedad. El estado económico de los procesados se enuncia en la primera parte de cada sentencia y en el fallo se aprueba el auto declarativo de insolvencia. Es abrumadora la mayoría de los encausados faltos de recursos y bienes: 1.585 (un $83 \%$ de los 1.977 encausados). Sólo 100 son declarados solventes, de ellos 20 lo son parcialmente. De 237 no se ofrecen datos.

El estado civil predominante entre el colectivo de mujeres estudiado es el de casada, con 493 casos (39,88\%), si bien de un modo discreto, pues es escasa la diferencia frente a las encuadradas dentro de la soltería, 473 (38,26\%). Las viudas son 261, una cifra considerable, pues representan un $21,11 \%$ del total de mujeres, lo que puede relacionarse a priori con la represión del régimen y las consecuencias de la guerra civil ${ }^{65}$. De 9 no tenemos ninguna información sobre su estado civil. El dato contrasta con el número de hombres viudos, solo 15 , apenas un $1,7 \%$. Precisamente los hombres participantes son mayoritariamente solteros (el 66,6 \% del total frente al 30,55 \% que representan los casados). El protagonismo de viudas y casadas es indicativo de la práctica delictiva como una estrategia de sustento familiar que apelaba a nociones morales compartidas por el resto de la comunidad. El régimen y la miseria las empujaron hacia los sectores marginales de la sociedad como si fueran «mujeres perversas o de dudosa moral $»^{66}$.

Del total de sentencias analizadas, y de las mujeres que por ellas desfilan, solo un $8 \%$ tienen antecedentes penales, en tanto que el $92 \%$ carece de ellos. La ausencia de antecedentes, unida a la notoria juventud de los procesados y al predominio de los insolventes permite hablar a algunos especialistas de "delincuencia de nuevo cuño» ${ }^{67}$.

Desde el punto de vista profesional, los porcentajes de las encausadas responden a los del censo socio profesional de la época: 978 quedan hegemónicamente agrupadas en el epígrafe de «sus labores», un $80 \%$ del total de las juzgadas. Otras 82 ejercían la misma labor pero al servicio de otras, como sirvientas o lavanderas.

Muchas mujeres humildes no traspasaron los límites de la legalidad gracias a la solidaridad de familiares y vecinos. Es el caso, por ejemplo, de Eugenia Mansilla, de Fontanosas (Ciudad Real ${ }^{68}$. En julio de 1941 fue fusilado su marido, Mateo Escribano. Eugenia se quedó sola a

64. Audiencia Provincial de Toledo, Libro de Sentencias, año 1944, Sentencia número 62.

65. En Murcia de todos los procesados por la Audiencia Provincial de Murcia entre 1939 y 1949 , las viudas representaban el 23,2 \%, siendo viudas relativamente jóvenes (el 37,6 \% tenían menos de cuarenta años (Gómez Westermeyer, op. cit., 80 y 96). En Almería las viudas sólo alcanzaban el 9,51 \% de las detenidas por la Guardia Civil (Rodríguez Barreira, loc. cit., 75).

66. P. Sánchez Sánchez, Individuas de dudosa moral. La represión de las mujeres en Andalucía (1936-1958), Barcelona, 2009.

67. Gómez Westermeyer, op. cit., 82.

68. J. López García, “Rescoldos”, en J. López García y F. Ferrándiz (Coords.), Fontanosas 1941-2006. Memoria de carne y hueso, Fontanosas, 2010, 180-181. 
cargo de siete hijos de edades comprendidas entre los veinte y un año. Pronto la familia quedó reducida a la mitad: Nemesio, el mayor, murió «reventado» después de llegar exhausto a su casa tras una jornada de dura siega en la que se azuzaba para trabajar más rápido. Francisco, el segundo, moriría fusilado. Inocenta, la mayor de las hermanas, murió con 14 o 15 años de un ataque al corazón. Victoria, la pequeña, también falleció como consecuencia de la mala atención sanitaria y de la precaria alimentación. Eugenia fue un modelo de sufrimiento, pero también de organización y resistencia, como otras muchas mujeres que se organizaban para llevar la comida, para transmitir ánimo y esperanza... Mujeres solas al frente de la casa por cuya fuerza y empeño salieron adelante numerosas familias españolas en tiempos muy difíciles.

\section{CONCLUSIONES}

Durante la posguerra (1939-1949), las mujeres españolas adquirieron un gran protagonismo en la lucha por la supervivencia de la unidad familiar. Muchas de ellas fueron «mujeres solas» que, con sus maridos en las cárceles o muertos en la guerra o a consecuencia de la represión del régimen vencedor, tuvieron que sacar adelante a sus familias. Prácticamente su único objetivo en estos años era sobrevivir, para lo que utilizaron numerosas estrategias, unas dentro de la legalidad y otras fuera de ella. Entre estas últimas, los archivos judiciales indican que destacaba la práctica del robo y el hurto.

Los delitos contra la propiedad fueron los más numerosos de los delitos comunes y los que llevaron a más mujeres a las cárceles. El porcentaje de presas penadas por este tipo de delitos económicos durante la posguerra fue en constante aumento respecto a los hombres, aunque aún seguían a larga distancia de ellos (entre el 8,5 y el $11 \%$, frente a una media del $5,1 \%$ de los años previos a la guerra). En muchos casos la delincuencia era planificada estratégicamente en la unidad familiar, para evitar las represalias políticas y los mayores castigos sobre los hombres, delinquiendo en mayor medida las mujeres y los niños, cuyas penas eran más suaves. Todos eran partícipes, aunque no fuesen imputados por la justicia.

La delincuencia no era una estrategia nueva, pues ya antes de la guerra la mujer protagonizaba muchos de los delitos contra la propiedad como medio de resistencia cotidiana. En Castilla-La Mancha, territorio investigado a través de los Libros de Sentencia de las Audiencias Provinciales, la delincuencia femenina se incrementó sobre todo después de perder las servidumbres colectivas tras la desamortización general iniciada en 1855 . Se trataba, fundamentalmente, de un medio de resistencia cotidiana frente al nuevo régimen liberal que privaba a muchas familias humildes de recursos que antes eran públicos y ahora ya eran propiedad privada. Aunque la justicia los condenaba, popularmente eran vistos como una tradición que debía ser consentida y protegida por todos.

En la posguerra, la mujer castellano-manchega va a delinquir sobre todo contra la propiedad, también en busca de recursos que le posibilitaran la subsistencia propia y la de sus familias. Los delitos contra la propiedad, como en el resto de territorios estudiados hasta ahora, representaron el mayor porcentaje (en este caso el 43,53\%), siendo las acciones mayoritarias el robo y el hurto $(91,88 \%)$, prueba de que sólo buscaban la supervivencia de la familia. No eran ni mucho menos delincuentes habituales, sino mujeres desesperadas, como 
Monográfico | Mujeres solas en la posguerra española (1939-1949). Estrategias frente al hambre y la represión

prueba que en una amplia mayoría no tenían antecedentes penales ( $92 \%$, porcentaje similar al de antes de la guerra). Tampoco cometieron acciones violentas en prácticamente ningún caso. La mayoría eran casadas o viudas $(60,99 \%$ ), con cargas familiares, que se vieron forzadas a arriesgar su libertad casi a diario por un plato de comida para sus hijos. Muchas de ellas eran mujeres solas, responsables únicas de la unidad familiar como víctimas indirectas de la guerra o la represión, como prueba el incremento de las viudas con respecto a antes de la guerra ( $21,11 \%$ de después del conflicto frente al 9,8\% de los años previos a él).

La resistencia cotidiana después de la guerra ya no tenía su escenario principal en los campos de cultivo privatizados por las desamortizaciones u otros procesos de desarticulación del comunal. La transgresión de la propiedad, el desafío a las leyes se extendía a los núcleos de población y a todo tipo de espacios y lugares en los que se podían encontrar productos para satisfacer necesidades individuales y familiares. 